\title{
RELATIVE EFFECTIVENESS OF METHODS FOR IMMUNIZING BALB/cwm MICE TO TRANSPLANTABLE MYELOMONOCYTIC LEUKEMIA*
}

\author{
Howard B. URnovitz and William H. MuRPhy \\ The Department of Microbiology, The University of Michigan Medical School, \\ Ann Arbor, MI 48109, U.S.A.
}

(Received 25 April 1979. Accepted 31 May 1979)

\begin{abstract}
An experimental model of transplantable myelomonocytic leukemia (WEHI-3B) was developed in syngeneic BALB/cwm mice to characterize immune mechanisms in this disease. The relative effectiveness of various methods for immunizing mice to transplantable myelomonocytic cells was analyzed. When mice were immunized i.p. once a week for 3 successive weeks with cell preparations $\left(10^{7}\right)$ inactivated by formalin they died at a faster rate than nonimmunized controls. When complete Freund's adjuvant was used to enhance the protective response immunized mice also died at a faster rate than the controls. If mice were immunized with various ratios of Xirradiated and viable tumor cells survival time was not increased. The most consistent result was accelerated death in the various experimental groups. When mice were immunized once weekly with X-ray inactivated cells $(5000 \mathrm{R})$ for 3,5 or 8 successive weeks, the survival frequency was approximately the same $(70-80 \%)$ in all three test groups. However, animals immunized 5 times withstood a higher challenge dose of tumor cells than those immunized 3 times. The spacings between immunizing doses and challenge appeared to significantly affect the efficacy of immunization. The age of mice had a significant effect on the protective response. When mice 6 weeks of age or younger were immunized the survival frequency was $<30 \%$, compared to $70-80 \%$ in mice 7 weeks to 8 months of age. Considered together the results of these studies show that tumor cells of the WEHI-3B line of transplantable myelomonocytic leukemia are similar to syngeneic P1798 transplantable lymphoma and the various BALB plasmacytomas in that they are only weakly immunogenic in the BALB/c strain. The results also suggest that the immunologic response of $\mathrm{BALB} / \mathrm{c}$ mice to weakly antigenic tumors is under strong negative regulation.
\end{abstract}

\section{INTRODUCTION}

ACUTE myelogenous leukemia is one of the most common forms of leukemia in adults. Since pure granulocytic or monocytic leukemia is uncommon, and because acute myelogenous leukemia involves both types of cell populations and their progenitors, the term acute myelomonocytic leukemia (AMML) has been used to signify that the disease involves a diversity of cell populations. The papers by Hayhoe and Cawley [10], and Saarni and Linman [29], discuss the complexities of nomenclature, an issue that cannot be considered in detail here. The important point is that the diversity of malignant cell populations involved in the pathogenesis of the disease has significantly limited the effectiveness of various chemotherapeutic regimens [2]. Paradoxically, there is also evidence indicating [reviewed in 19] that AMML is more responsive to immunotherapy than acute lymphocytic leukemia (ALL). This paradox may be accounted for in a number of ways: the immune response in AMML may recognize an antigen that is common to the diverse cell types found in the disease, tumor cell kill may be nonspecific, AMML is not as destructive to lymphoid tissues as ALL and therefore is not as immunologically debilitating, etc. To

Abbreviations; $A M M L$, Acute myelomonocytic leukemia; $A L L$, Acute lymphocytic leukemia; $M B S S$, Möller's balanced salt solution; FSP, Formalin inactivated WEHI cells of the splenic transplant line; $F I P$, Formalin inactivated WEHI cells of the peritoneal transplant line; $C F A$, Complete Freund's adjuvant.

* This work was supported by grant ACS-CH-84 from The American Cancer Society. 
discriminate among these possibilities basic data are needed on the nature of the immune response to AMML and the protective mechanisms involved.

Although there is an extensive literature on the immune response to various lymphoid neoplasms [13] in mice, corresponding information on AMML is largely lacking. Transplantation models of the disease have been confined largely to the rat. The model of myelomonocytic leukemia (L5222) in syngeneic BDIX rats described by Hoelzer [11] is a particularly acute disease $\left(10^{2}\right.$ leukemic cells are lethal in 12-13 days) and has been used primarily for pharmokinetic studies [9]. The transplantable "myeloblastic leukemia" in Donryu rats described by Aoshima and Ishidate [1] also is highly malignant $\left(10^{3}\right.$ leukemic cells are lethal in 13-18 days). Unfortunately, the various cloned transplantation lines studied in this model are unstable on serial passage [1]. The only detailed immunologic studies of myelomonocytic leukemia in the rat that could be found were those of Wrathmell and Alexander [34] who were unable to immunize syngeneic August rats to the highly lethal ( $10^{2}$ leukemic cells killed syngeneic rats in 14-23 days) SAL line of transplantable tumor cells. Van Bekkum and Hagenbeek recently described [32] a transplantable model of promyelomonocytic leukemia in BN rats that may be more suitable for immunologic studies. In this model there was a linear relationship between the $\log _{10}$ of viable leukemic cells injected and the time in days until death. Low doses of tumor cells $\left(10^{3}\right)$ required from 40 to 45 days to kill recipient animals. Because the tumor is slow growing there is sufficient time to permit the generation of a protective immune response. We were able to find only one paper each on transplantable "myeloid leukemia" in the hamster [22] and in the guinea pig [6]. In contrast, there have been extensive immunologic studies [20] on a transplantable B cell guinea pig leukemia.

To analyze immunologic mechanisms in AMML a transplantable model in inbred mice would offer a number of important advantages: (1) a variety of inbred mice of different genotypes are available so that immunologic mechanisms can be analyzed genetically; (2) animals can be produced in the numbers needed for the precise quantification of in vivo protective mechanisms [14]; and (3) reagents are available to evaluate the role of C-type viruses in the pathogenesis of the disease [23]. Preisler et al. [26] and Husseini et al. [12] have used RFM transplantable "myeloid leukemia" in RFM/UN mice for pathophysiologic and pharmokinetic studies. This experimental disease appears to be primarily a "granulocytic" leukemia.

The only description in the literature of acute myelomonocytic leukemia in mice that we could find is the WEHI model reported by Warner et al. [33]. The original WEHI tumor served as the source [33] of four sublines designated A, B, C and D. The A and D sublines were chloromas. The $B$ and $C$ sublines were similar to those in humans in a number of respects [33]. To develop a transplantable model of the disease suitable for immunologic studies we characterized in detail [21] the hematologic and histopathologic properties of the WEHI-3B cell subline, thus confirming and extending the original findings of Warner et al. [33]. Three sublines of the WEHI-3B line were developed by us [21]. The subcutaneous (SQ) transplant line served as a model for solid tumor growth. The intraperitoneal (IP) and splenic (SP) lines served as models of diffuse tumor growth. All three sublines are stable on serial transplantation and the time in days until death is a linear function of the $\log _{10}$ of viable tumor cells injected into syngeneic BALB/c mice [21]. All three sublines approximate single cell kill and are lethal in 20-30 days [21].

The current report is the first in a series of papers dealing with the nature of the protective immune response of BALB/c mice to myelomonocytic leukemia. Most of the studies have been carried out with the IP line of WEHI tumor cells. Unlike the Friend virus induced myeloid leukemias [8], WEHI tumor cells are only weakly immunogenic. This report defines the narrow range over which immunization elicits a protective response. 


\section{MATERIALS AND METHODS}

Mice

Inbred mice of the BALB/cwm strain (referred to as BALB mice hereafter) were obtained from our breeding stocks. The lineage of the strain and hematologic properties of the mice were described previously [24]. Female mice were used for all experiments unless stated otherwise.

\section{Transplantable WEHI-3B myelomonocytic leukemia}

The WEHI-3B line was obtained from Dr. D. Metcalf of the Walter and Eliza Hall Institute of Medical Research, Melbourne, Australia. On receipt the subcutaneous tumor was transplanted immediately into our strain of mice. The methods used to develop the subcutaneous (SQ), splenic (SP) and intraperitoneal (IP) sublines were described previously [21]. The SP subline was derived from the subcutaneous tumor by the intraperitoneal injection of a $20 \%$ suspension of tumor cells. Thereafter spleen cells from mice moribund from leukemia were used for serial passage by the i.p. route. Because the original sublines of WEHI employed by Warner $e t$ al. [33] underwent significant variation on serial passage in their hands, we serially passed the SP line 25 times to adapt it fully to the splenic growth form. Monodisperse spleen cell suspensions of the SP subline were washed twice in a balanced salt solution designated MBSS [17]. Viable cell counts were done by the Trypan Blue dye exclusion technique. For routine passage $10^{6}$ viable cells were injected i.p. The IP subline was derived from mice that had been inoculated with passage 27 of the SP subline. However, peritoneal cells obtained from mice moribund from leukemia were used for serial passage by the i.p. route instead of spleen cells. For routine passage $6 \mathrm{ml}$ of MBSS were injected i.p. into mice moribund from leukemia, the abdominal cavity was gently massaged, and the fluid withdrawn with an $\mathbf{1 8}$ gauge needle and syringe. Cells were washed twice and counted. Viability consistently was $95-100 \%$. Results from dose-response, hematologic and histopathologic studies were reported [21].

\section{Formalin inactivated cells}

Cells of the IP or SP sublines were inactivated with formalin. Fresh tumor cell suspensions were made containing $2 \times 10^{7}$ cells per $\mathrm{ml}$ of MBSS. A stock formalin solution was made by diluting $37.4 \%(\mathrm{~g} / 100 \mathrm{ml})$ of analytical grade formaldehyde 10-fold in MBSS. A fresh working solution was prepared by diluting the stock formalin $1: 250$ in cold $\left(4^{\circ} \mathrm{C}\right)$ MBSS. Tumor cells $\left(2 \times 10^{7}\right.$ per $\left.\mathrm{ml}\right)$ were mixed with an equal volume of the diluted formalin solution and incubated at $4^{\circ} \mathrm{C}$ for $18 \mathrm{~h}$.

\section{$X$-irradiated cells}

Cells were inactivated as described previously [14]. Thus, cells in $10 \mathrm{ml}$ aliquots $\left(10^{7}-10^{8}\right.$ per ml of MBSS) were dispensed into $60 \mathrm{~mm}$ dishes and exposed to X-rays generated by a Coronado X-Ray Therapy Machine (Westinghouse Corp.). A dose of $537.5 \mathrm{R} / \mathrm{min}$ was delivered at room temperature for $9.3 \mathrm{~min}(5000 \mathrm{R})$ at a distance of $24 \mathrm{~cm}$ (X-rays generated at $200 \mathrm{kV}, 15 \mathrm{~mA}$, using a $1 \mathrm{~mm} \mathrm{Al} \mathrm{filter).}$

\section{Complete Freund's adjuvant}

WEHI cells $\left(2 \times 10^{7}\right.$ per $\left.\mathrm{ml}\right)$ inactivated by formalin or X-irradiation as described above were emulsified in an equal volume of complete Freund's adjuvant (Difco Laboratories, Detroit, MI).

\section{Admixtures of viable and $X$-irradiated cells}

The methods used to prepare admixtures of viable and X-irradiated cells were described previously [15]. In these experinents only the IP subline of WEHI cells were used. Viable and X-irradiated IP cells were mixed in various proportions (Table 3 ) immediately before $1 \mathrm{ml}$ of the admixture was injected i.p.

\section{Statistical methods}

Survival data were analyzed as described previously $[15,16]$ using the Michigan Interactive Data Analysis System (MIDAS) which is a subroutine of the Michigan Terminal System. However, in immune mice the survival times in days was not normally distributed. Therefore, differences in survival times in days were analyzed using nonparametric multisample comparisons as described by Conover [4]. The Mann-Whitney test was used for comparisons of two independent samples. The Kruskal-Wallis test was employed when three or more samples were compared. Differences in survival frequencies were analyzed by the chi-square test as described by Dixon and Massey [5]. 


\section{RESULTS}

Failure to elicit a protective response with formalin inactivated WEHI cells

In previous studies $[15,16]$ we were able to demonstrate that weakly antigenic tumor cells elicited a protective response providing that an appropriate dose-regimen of formalin inactivated cells was used for immunization. The objective of the current experiments was to determine whether BALB mice could be immunized similarly to a low challenge dose ( $10^{3}$ viable cells) of WEHI tumor cells. Initial experiments were done with the IP and SP tumor transplant lines because of the possibility that they might differ significantly in immunogenicity. Data representative of a large number of experiments are presented in Table 1. Mice that received one or two i.p. injections of formalin inactivated SP (FSP) cells

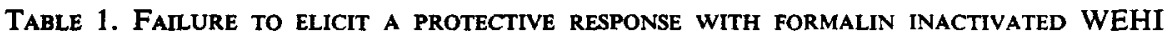
CELLS

\begin{tabular}{|c|c|c|c|c|c|}
\hline Expt. No. & Treatment* & $\begin{array}{c}\text { Challenge } \dagger \\
\text { dose }\end{array}$ & Survivors & $\begin{array}{c}\text { Median survival } \\
\text { time (days) }\end{array}$ & $P$ value $\neq$ \\
\hline \multirow[t]{4}{*}{1} & MBSS-1X & $10^{3}$ & $0 / 10$ & 22.7 & \\
\hline & FSP-1X & $10^{3}$ & $0 / 9$ & 22.2 & 0.10 \\
\hline & MBSS-2X & $10^{4}$ & $0 / 10$ & 20.2 & \\
\hline & FSP-2X & $10^{4}$ & $0 / 5$ & 19.0 & 0.10 \\
\hline \multirow[t]{5}{*}{2} & MBSS-3X & $10^{4}$ & $0 / 5$ & 18.3 & \\
\hline & FSP-3X & $10^{4}$ & $0 / 5$ & 16.2 & 0.02 \\
\hline & MBSS-3X & $10^{3}$ & $0 / 10$ & 21.9 & \\
\hline & FSP-3X & $10^{3}$ & $0 / 10$ & 19.2 & 0.004 \\
\hline & FSP-3X & - & $5 / 5$ & - & \\
\hline \multirow[t]{3}{*}{3} & MBSS-3X & $10^{3}$ & $0 / 12$ & 22.4 & \\
\hline & FIP-3X & $10^{3}$ & $0 / 12$ & 21.1 & 0.03 \\
\hline & FIP-3X & 一 & $9 / 9$ & 一 & \\
\hline
\end{tabular}

* Six week old mice were given 1, 2 or 3 serial i.p. injections (spaced 1 week apart) of formalinized WEHI cells of the splenic (FSP) or peritoneal (FIP) passage lines. Tumor cells were inactivated by incubation in $1: 5000$ formalin for $18 \mathrm{~h}$ at $4^{\circ} \mathrm{C}$. Control mice received an injection of balanced salt solution (MBSS) in place of inactivated tumor cells.

+ One week after the last immunization mice were challenged by the i.p. injection of either $10^{3}$ or $10^{4}$ viable tumor cells of the appropriate passage line.

$\ddagger$ Differences in median survival times were analyzed by the Mann-Whitney test as described in the text.

spaced 1 week apart died at the same rate as control mice (experiment 1). When mice received three weekly injections of formalinized cells of either the SP or IP subline they consistently died at a faster rate than the nonimmunized controls (experiments 2 and 3 ). To test whether formalin treatment inactivated tumor cells, mice received identical immunizations with formalinized cells but were not challenged (experiments 2 and 3). All of the mice survived immunization. Since the IP and SP sublines approximate single cell kill [21] these results provide reasonable evidence that mice were not dying from viable cells contained in the formalinized preparations.

\section{Effect of complete Freund's adjuvant (CFA) on the protective immune response}

To test whether CFA augmented a protective response, WEHI tumor cells of the IP passage line were emulsified in CFA and injected subcutaneously in each of four sites $\left(2.5 \times 10^{6}\right.$ cells $/$ site $)$. The cells used for immunization were inactivated either with formalin as described above or with $5000 \mathrm{R}$ of $\mathrm{X}$-irradiation. Cells were injected proximal to the draining inguinal or axillary lymph nodes of each leg to assure that the lymphoid cells in each of the draining nodes would have a maximal opportunity to be sensitized by antigen. Injections were made once a week for 3 successive weeks. The results show (Table 2) that the mice which received injections of CFA alone, or tumor cells suspended in CFA, died at a faster rate than the controls. 
TABle 2. EfFect of CFA on the Protective Response to WEHI

\begin{tabular}{lccc}
\multicolumn{4}{c}{ CELLS } \\
\hline Treatment* & Survivors & $\begin{array}{c}\text { Median survival } \\
\text { time (days) }\end{array}$ & $P$ value $\dagger$ \\
\hline MBSS & $0 / 10$ & 22.5 & \\
MBSS :CFA & $0 / 10$ & 20.0 & $0.003 \ddagger$ \\
XIP & $1 / 10$ & 23.0 & $0.05 \ddagger$ \\
XIP:CFA & $0 / 10$ & 20.3 & $0.0004 \ddagger$ \\
FIP & $0 / 10$ & 23.5 & 20.3 \\
FIP-CFA & $0 / 10$ & &
\end{tabular}

* Only tumor cells of the IP passage line were used. They were inactivated with X-irradiation (XIP) or formalin (FIP) as described in the text. The immunogenicity of cells emulsified in CFA was compared with controls in which CFA was deleted. Preparations $\left(2 \times 10^{6}\right.$ cells) were injected s.q. into each leg proximal to the draining inguinal or axillary lymph nodes. Injections were made once a week for 3 successive weeks. One week after the last injection mice were challenged by the intrascapular injection of $10^{4}$ viable tumor cells.

+ See footnote $\ddagger$, Table 1.

$\ddagger$ Compared to the preparation without CFA.

TABle 3. FaILURe to elicit a PRotective Response With admixtures of Viable AND X-IRRADIATED WEHI CELLS

\begin{tabular}{|c|c|c|c|c|}
\hline Group & Treatment* & Survivors & $\begin{array}{l}\text { Median survival } \\
\text { time (days) }\end{array}$ & $P$ value \\
\hline \multirow[t]{6}{*}{1} & $3 \mathrm{~V}: 0 \mathrm{X}$ & $0 / 12$ & 23.8 & \\
\hline & $3 V: 3 X$ & $0 / 12$ & 24.3 & NS \\
\hline & $3 V: 4 X$ & $0 / 11$ & 23.8 & NS \\
\hline & $3 V: 5 x$ & $0 / 12$ & 22.8 & 0.03 \\
\hline & $3 V: 6 X$ & $0 / 12$ & 21.9 & $<0.001$ \\
\hline & $3 V: 7 X$ & $0 / 8$ & 22.3 & NS \\
\hline \multirow[t]{6}{*}{2} & $4 V: 0 X$ & $0 / 12$ & 23.8 & \\
\hline & $4 V: 3 X$ & $0 / 12$ & 20.9 & 0.02 \\
\hline & $4 V: 4 X$ & $0 / 12$ & 21.9 & 0.03 \\
\hline & $4 V: 5 X$ & $0 / 12$ & 21.4 & 0.02 \\
\hline & $4 V: 6 X$ & $0 / 12$ & 20.9 & 0.01 \\
\hline & $4 V: 7 X$ & $0 / 8$ & 18.6 & $<0.01$ \\
\hline \multirow[t]{6}{*}{3} & $5 V: 0 X$ & $0 / 12$ & 19.4 & \\
\hline & $5 V: 3 X$ & $0 / 12$ & 19.1 & NS \\
\hline & $5 V: 4 X$ & $0 / 12$ & 19.1 & NS \\
\hline & $5 V: 5 X$ & $0 / 11$ & 18.4 & NS \\
\hline & $5 V: 6 X$ & $0 / 12$ & 18.1 & NS \\
\hline & $5 V: 7 X$ & $0 / 8$ & 17.9 & 0.04 \\
\hline \multirow[t]{6}{*}{4} & $6 V: 0 X$ & $0 / 12$ & 16.6 & \\
\hline & $6 V: 3 X$ & $0 / 12$ & 17.0 & NS \\
\hline & $6 V: 4 X$ & $0 / 12$ & 16.3 & NS \\
\hline & $6 \mathrm{~V}: 5 \mathrm{X}$ & $0 / 12$ & 16.6 & NS \\
\hline & $6 V: 6 X$ & $0 / 11$ & 15.8 & NS \\
\hline & $6 V: 7 X$ & $0 / 8$ & 15.6 & 0.02 \\
\hline \multirow[t]{5}{*}{5} & $7 V: 0 X$ & $0 / 8$ & 14.5 & \\
\hline & $7 V: 4 X$ & $0 / 7$ & 13.9 & NS \\
\hline & $7 \mathrm{~V}: 5 \mathrm{X}$ & $0 / 8$ & 13.3 & NS \\
\hline & $7 V: 6 X$ & $0 / 8$ & 13.2 & NS \\
\hline & $7 V: 7 X$ & $0 / 8$ & 13.3 & NS \\
\hline
\end{tabular}

* WEHI tumor cells of the IP line were inactivated by $5000 \mathrm{R}$ of $\mathrm{X}$-irradiation. Each mouse in each test group received a single $1 \mathrm{ml}$ i.p. injection that contained the $\log _{10}$ number of viable (V) or X-irradiated (X) cells indicated. One week after immunization all mice were challenged by the i.p. injection of $10^{3}$ viable tumor cells. All mice were 6-8 weeks old when immunized; only females were used.

+ See footnote $\ddagger$, Table 1 . The $P$ values compare each of the data sets with mice that received no $(0 \mathrm{X})$ irradiated tumor cells; NS, no significant difference. 
Failure to elicit a protective response with admixtures of viable and X-irradiated WEHI tumor cells

In previous studies $[15,16]$ we documented that the immune response to weakly antigenic malignant lymphocytes was superior when admixtures of $\mathrm{X}$-irradiated and viable tumor cells were used for immunization. Since the results presented in Tables 1 and 2 indicated that WEHI cells were only weakly immunogenic, an attempt was made to demonstrate a protective immune response by the use of admixtures of killed and viable WEHI cells for immunization. In these experiments only tumor cells of the IP subline were used. To assess their X-ray sensitivity WEHI cells ( $10^{9}$ viable cells contained in $10 \mathrm{ml}$ of MBSS) were placed in $60 \mathrm{~mm}$ plastic culture dishes and irradiated at a dose of $537.5 \mathrm{R}$ per min at room temperature. The dose range used was from 0 to $15,000 \mathrm{R}$. Mice in groups of 12 were used to test $\mathrm{X}$-irradiated cells for viability. Since a single cell of the IP line is lethal to mice [21] reasonably accurate data were obtained: $12 / 12$ mice died when cells received $500 \mathrm{R} ; 1 / 12$ deaths at $1000 \mathrm{R}$; and $0 / 12$ deaths at $\mathrm{X}$-ray doses of $5000,10,000$ or $15,000 \mathrm{R}$. Thus, $5000 \mathrm{R}$ was used as a standard to inactivate WEHI cells.

TABLE 4. EFFECT OF DOSE-REgIMEN ON THE IMMUNE RESPONSE TO WEHI TUMOR CELLS

\begin{tabular}{|c|c|c|}
\hline Method of immunization* & Survivors $\dagger$ & Per cent survivors \\
\hline \multicolumn{3}{|l|}{ Experiment 1 : a single immunization } \\
\hline (a) Mice challenged 1 week later & $0 / 20$ & 0 \\
\hline (b) Mice challenged 2 weeks later & $0 / 10$ & 0 \\
\hline (c) Mice challenged 3 weeks later & $0 / 20 \quad(2)$ & 0 \\
\hline \multicolumn{3}{|l|}{ Experiment 2: two immunizations spaced } \\
\hline (a) 1 week apart & $13 / 40 \quad(3)$ & 33 \\
\hline (b) 2 weeks apart & $38 / 50 \quad(4)$ & 76 \\
\hline (c) 3 weeks apart & $22 / 39 \quad(3)$ & 56 \\
\hline \multicolumn{3}{|l|}{ Experiment 3: three immunizations spaced } \\
\hline (a) 1 week apart & $105 / 157(8)$ & 67 \\
\hline (b) 2 weeks between first and second & $7 / 10(1)$ & 70 \\
\hline $\begin{array}{l}\text { (c) } 1 \text { week between first and second with a } 2 \text { week skip } \\
\text { between second and third } \\
\text { (d) } 3 \text { weekly immunizations; challenge } 2 \text { weeks after the }\end{array}$ & $10 / 10 \quad(1)$ & 100 \\
\hline last immunization & $9 / 22 \quad(2)$ & 41 \\
\hline Experiment 4: five immunizations spaced 1 week apart & $21 / 25 \quad(2)$ & 84 \\
\hline Experiment 5: eight immunizations spaced 1 week apart & $18 / 22(2)$ & 82 \\
\hline
\end{tabular}

* Mice 8-12 weeks old were used for experiments 1, 2 and 3. In experiment 4 one group was 5 weeks old and the other 8 weeks old at the start of serial immunizations. Mice received from two to eight serial i.p. injections of $10^{7} \mathrm{X}$-irradiated ( $\left.5000 \mathrm{R}\right) \mathrm{WEHI}$ cells spaced as indicated. Mice were challenged by the i.p. injection of $10^{3}$ viable WEHI cells 1 week after the last immunization or as noted in the table.

$\dagger$ The numbers in brackets indicates the number of replicate experiments.

In Table 3 various proportions of viable $(V)$ and $X$-irradiated cells $(X)$ were combined so that $1 \mathrm{ml}$ of cell suspension contained the indicated numbers. None of the preparations elicited a protective response. The most consistent result was accelerated death. The effect was most marked in the group 2 animals.

\section{Immunogenicity of $X$-irradiated cells given in various dose regimens}

Multiple injections of inactivated cells are required to elicit a protective response with weakly antigenic tumors $[15,16,30]$. Systematic studies therefore were carried out to determine the optimum dose-regimens for immunizing mice to X-irradiated cells of the IP line of WEHI tumor cells. Table 4 shows the results when mice received from one to eight serial injections of $10^{7} \mathrm{X}$-irradiated WEHI cells spaced in various ways, and then were challenged at various times after the last immunization. When mice received a single i.p. injection of 
$10^{7} \mathrm{X}$-irradiated WEHI cells none survived. An increase in survival time could be detected only if mice were challenged $2-3$ weeks after immunization (data not shown). When mice received two immunizations spaced 1 week apart, survival approximated $33 \%$ (experiment 2a). When the second immunization was given 2-3 weeks after the first, survival was increased. In experiment 3 mice were given three immunizations spaced in various ways. The results of experiments (a) and (b) were essentially the same. The results of (d) differed from (a) and (b) or (c). Our experience with this model suggests that (c) was not different from (a) and (b). The mice in group $d$ had a lower survival frequency than those in $a, b$ and $c$, thus suggesting that immunity waned rather rapidly after the last immunization. The table (experiments 4 and 5) also shows that mice given five to eight serial immunizations did not have a survival frequency greater than those given three immunizations. Overall, the most consistent results were obtained when mice were immunized 3 times spaced 1 week apart and challenged 1 week after the last immunization (70-80\% survival). Accordingly, this technique was adopted as the standard for immunization.

\section{Level and duration of immunity}

Although the data in Table 4 indicated that the survival frequencies of mice immunized from 3 to 8 times were essentially the same, the possibility existed that the immune response differed quantitatively. To document whether such a difference existed, mice were immunized weekly 3-5 times with X-irradiated tumor cells and challenged 1 week after the last immunization with from $10^{3}$ to $10^{5}$ viable WEHI tumor cells. The data in Table 5 show that the level of resistance elicited by five serial immunizations was higher than that observed when mice received three serial immunizations. Table 6 shows that the maximum level of immunity (approximately $85 \%$ survival) persisted for only 1-3 weeks after mice were immunized 3 times at weekly intervals.

Table 5. LeVel of Resistance induced by mmunization with X-irRadiated WEHI TUMOR CELLS

\begin{tabular}{cccc}
\hline $\begin{array}{c}\text { Number of weekly* } \\
\text { injections }\end{array}$ & $\begin{array}{c}\text { Challenget } \\
\text { dose }\end{array}$ & Survivors $\ddagger$ & Per cent survivors \\
\hline 3 & $10^{3}$ & $22 / 27(2)$ & 81 \\
5 & $10^{3}$ & $13 / 15(1)$ & 87 \\
3 & $10^{4}$ & $7 / 27(2)$ & 26 \\
5 & $10^{4}$ & $12 / 15(1)$ & 80 \\
3 & $10^{5}$ & $2 / 27(2)$ & 7 \\
5 & $10^{5}$ & $5 / 15(1)$ & 33
\end{tabular}

* Ten to twelve week old female mice given three or five weekly injections of $10^{7} \mathrm{X}$-irradiated WEHI cells were challenged 1 week after the last immunization as indicated.

$\dagger$ Mice were challenged by the i.p. injection of $10^{3}-10^{5}$ viable WEHI cells as indicated.

$\ddagger$ The number of replicate experiments is shown in brackets.

Table 6. Persistence of immunity

\begin{tabular}{crcc}
\hline $\begin{array}{c}\text { Time of challenge* } \\
\text { (weeks) }\end{array}$ & Survivorst & Per cent survival & P value \\
\hline 1 & $23 / 27(2)$ & 85 & \\
2 & $7 / 12(1)$ & 58 & 0.15 \\
3 & $8 / 12(1)$ & 67 & 0.37 \\
4 & $15 / 27(2)$ & 55 & 0.04 \\
10 & $7 / 15(1)$ & 46 & 0.02 \\
\hline
\end{tabular}

* Female mice 8-10 weeks old received three serial i.p. injections spaced 1 week apart of $10^{7} \mathrm{X}$-irradiated WEHI cells and were challenged i.p. as indicated with $10^{3}$ viable cells.

$\dagger$ The number of replicate experiments is shown in brackets.

¥ The chi-square test was used to compare all groups of mice with those challenged at 1 week. 


\section{Effect of age and sex on the immune response}

During the experiments described above it was observed that both the age and sex of mice appeared to affect the immune response to X-irradiated WEHI tumor cells. Experiments were therefore carried out to define the magnitude of such effects. Table 7 shows that 4-6 week old mice were less effective in developing a protective response than those 7 weeks to 8 months of age. Differences in the response of mice among the 7 week to 8 month age groups did not differ statistically. Overall $143 / 184$ mice in these groups survived immunization and challenge (approximating an $80 \%$ survival frequency). The sex of mice did not affect survival frequency, viz., $27 / 40$ female survivors (68\%) compared with 19/40 male survivors $(48 \%)$ in two replicate experiments $(P=0.07)$.

TABLE 7. EFFECT OF AGE ON THE IMMUNE RESPONSE OF BALB MICE TO WEHI TUMOR CELLS

\begin{tabular}{ccc}
\hline $\begin{array}{c}\text { Age of mice at the first } \\
\text { immunizing injection }\end{array}$ & Survivors $\dagger$ & Per cent survival $\ddagger$ \\
\hline 4 weeks & $1 / 14(1)$ & 7 \\
6 weeks & $14 / 50(3)$ & 28 \\
7 weeks & $8 / 12(1)$ & 67 \\
8 weeks & $17 / 22(2)$ & 77 \\
10 weeks & $52 / 67(4)$ & 78 \\
11 weeks & $6 / 9(1)$ & 67 \\
12 weeks & $33 / 45(3)$ & 73 \\
4 months & $15 / 15(1)$ & 100 \\
8 months & $12 / 15(1)$ & 80 \\
\hline
\end{tabular}

- Mice received three serial i.p. injections of $10^{7}$ X-irradiated WEHI tumor cells spaced 1 week apart and were challenged by the i.p. injection of $10^{3}$ viable WEHI cells 1 week after the last immunization.

$\dagger$ The number of replicate experiments is shown in brackets.

$\ddagger$ The data for mice 7 weeks to 8 months of age did not differ significantiy $(P=0.4)$. The results for 4 week old mice did not differ from those for 6 week old mice $(P=0.1)$. Results for the 4-6 week old mice differed significantly $(P=0.000)$ from those for the 7 week to 8 month old group.

\section{DISCUSSION}

The results reported here indicate that the WEHI line of transplantable myelomonocytic leukemia is only weakly immunogenic in syngeneic BALB/cwm mice. It therefore differs significantly from the Friend-Moloney-Rauscher virus induced myeloid or lymphoid malignancies which elicit a strong protective immunologic response [7,8]. For example, when mice were immunized with formalin inactivated cells (Table 1) and then challenged with a minimum dose $\left(10^{3}\right)$ of viable tumor cells, they died at a faster rate than nonimmunized controls. Table 2 shows that when mice were immunized with formalin or X-ray inactivated cells emulsified in CFA and then were challenged, they also died at a faster rate than the nonimmunized controls. This result occurred despite the fact that multiple injections of inactivated cells were made by the subcutaneous route in a way to assure that draining lymph node cells were exposed to antigens. In similar studies of a weakly immunogenic transplantable lymphoma (line Ib leukemia in syngeneic C58 mice) we documented [16] that a strong protective response could be elicited if mice were immunized with a single i.p. injection of an admixture containing $10^{7} \mathrm{X}$-irradiated and $10^{3}$ viable tumor cells. When this technique was used in attempts to immunize BALB mice to WEHI cells (Table 3 ) again the most consistent response was accelerated death.

The results summarized in Tables $1-3$ could be interpreted in several ways: (1) if WEHI cells were only weakly immunogenic and consisted of populations of different antigenicities, a broadly protective response might not be elicited; (2) in the WEHI model the methods used to elicit a protective response to a weak tumor antigen may have been ineffective because 
the techniques employed may have preferentially elicited a suppressive rather than a protective response [3]; and (3) the poor protective response seen in Tables 1-3 may not have been a characteristic of myelomonocytic leukemia, but was instead an example of how a host of a given genotype may manifest an immune response to weakly antigenic tumor cells, i.e. one in which the predominant response is one of negative regulation [3]. As discussed below, a number of lines of evidence favor hypothesis 3 .

Our initial interpretation of the results presented in Tables 1-3 was that there was an active immune response. However, it was one in which suppressive mechanisms predominated, thus resulting in accelerated death. A systematic study therefore was done with X-ray inactivated cells $(5000 \mathrm{R})$ which sought to identify a dose-regimen of immunization that preferentially elicited a protective rather than a suppressive response (accelerated death). Table 4 presents representative results from an extensive series of experiments [31]. When mice received a single immunization and were challenged one or three weeks later, there were no survivors. However, when mice were challenged 2 or 3 weeks after immunization survival time was increased. This suggested that the timings of immunization and challenge were of key importance in eliciting a protective response. We therefore scheduled immunizations and challenge in such a way that protective, rather than suppressive, responses might be preferentially activated. In carefully controlled experiments it was possible to demonstrate a superior survival frequency when two immunizations were spaced 2 or 3 weeks apart (Table 4 , experiments $2 b$ and c). In experiments in which mice received three immunizations spaced in various ways (Table 4) limits in the statistical reproducibility of the assays did not permit a clear-cut distinction to be made among groups (a), (b) and (c) unless enormous numbers of mice were used, i.e. under experimental conditions where survival was consistently high (70-100\%). This limitation also applied to experiments 4 and 5 where mice received either five or eight serial immunizations.

Our impression that the immune response of BALB mice to WEHI cells was under strong negative regulation was strengthened by the results presented in Table 5 . Although these data clearly show that mice immunized serially 5 times at weekly intervals withstood a higher challenge dose of viable tumor cells than those immunized 3 times, the level of immunity elicited was not particularly high compared to similar studies done with weakly immunogenic line Ib lymphoma cells in syngeneic C58 mice $[15,16]$. In the later model a single injection of formalin or X-ray inactivated cells protects mice to a $10^{7} \mathrm{LD}_{100}$ challenge dose of tumor cells and immunity persists at high levels for more than 30 weeks [14]. In the WEHI model immunity begins to wane 1-2 weeks after the last immunizing injection (Table 4, experiment $3 \mathrm{~d}$ and Table 6). Further support for the view that the protective response to WEHI cells may be under strong negative regulation was obtained by the data summarized in Table 7. It was not possible to elicit a significant protective response in mice less than 7 weeks of age, a finding consistent with the observation [18] that suppressive mechanisms are strongest in young immunologically immature mice. In preliminary experiments we also have found [31] that mice could be effectively immunized if they were pretreated with an appropriate dose of cyclophosphamide, a procedure that inactivates suppressor $T$ cells [27]. Considered together the described results indicate that the protective immune response of $\mathrm{BALB} / \mathrm{cwm}$ mice to WEHI cells is under strong negative regulation and may be suppressor cell mediated.

At first glance our data also suggest that WEHI myelomonocytic leukemia cells are distinguished by the fact that they are only weakly immunogenic and that this may be an important causal factor in the pathogenesis of this disease. Although such an interpretation may be correct, a consideration of several representative tumor models in the BALB/c strain cautions against such a restrictive interpretation and leads to a more general hypothesis: in the BALB/c strain the predominant response to weak tumor antigens may be one 
of strong negative regulation. A number of lines of evidence are consistent with the more generalized hypothesis. For example, Prager et al. found [25] that P1798 lymphoma cells were only marginally immunogenic in syngeneic BALB/c mice even after cells were modified chemically in a variety of ways to enhance their immunogenicity. Protection to low doses of challenge tumor cells $\left(10^{3}\right.$ or $\left.10^{4}\right)$ could be achieved only when mice received 12-13 serial i.p. injections of modified cells at weekly intervals. In their review of the immunogenicity of various plasmacytomas induced in BALB/c mice by mineral oil or by other methods, Röllinghoff et al., [28] pointed out that such tumors are only weakly antigenic and that a protective response is difficult to elicit even when mice receive multiple injections of inactivated cells at weekly intervals.

In conclusion, it may be helpful for future work to consider that the protective responses of inbred mice to weak tumor antigens is divisible into two broad categories. One class of response is exemplified by the line Ib-C58 experimental model $[15,16]$ where the immune response is not under strong negative regulation. In this class of responses the problem is mainly one of finding the dose-regimen of immunization that elicits a high level of protection. The L1210 model of transplantable lymphoma in DBA mice also appears to fit into this category. In the second class suppressive mechanisms predominate. In such models the mouse genotype strongly regulates a negative response and suppressive immune mechanisms predominate, i.e. immunity is difficult to elicit, does not reach high levels, and does not persist at high levels. The P1798 transplantable lymphoma [25] and the various BALB/c plasmacytomas [34] may be representative of this type of response. The WEHI model of AMML also appears to fit into this category.

\section{REFERENCES}

1. Aoshima M. \& Ishidate M., JR. (1976) Alteration of biological behavior of rat leukemia by different routes of passage. J. natn. Cancer Inst. 56, 769.

2. Bodey G. P. \& Rodriguez V. (1978) Approaches to the treatment of acute leukemia and lymphomas in aduits. Seminars Hemat. 15, 221.

3. Broder S., MuUl L. \& WALdmanN T. A. (1978) Suppressor cells in neoplastic disease. J. natn. Cancer Inst. 61, 5.

4. CoNover W. J. (1976) Practical Nonparametric Statistics. Wiley, New York.

5. Dixon W. J. \& MAssey F. J., JR. (1969) Introduction to Statistical Analysis, 3rd ed. McGraw-Hill, New York.

6. Evans W. H., Mage M. G., Hsu C. K., Himmelhoch S. R. \& Smrth G. H. (1978) Transplantable granulocytic leukemia in strain 13 guinea pigs. Cancer Res. 38, 130.

7. FASS L. \& FEFER A. (1972) Factors related to therapeutic efficacy in adoptive chemoimmunotherapy of a Friend virus-induced lymphoma. Cancer Res. 32, 2427.

8. Freedman H. A., Lilly F. \& Steeves R. A. (1975) Antigenic properties of cultured tumor cell lines derived from spleens of Friend virus-infected BALB/c and BALB/c-H-2 ${ }^{b}$ mice. J. exp. Med. 142, 1365.

9. Harriss E. B. \& Hoelzer D. (1978) Proliferative state of normal in vitro colony forming cells during development of L5222 rat leukemia and their reaction to chemotherapy. Blood 51, 221.

10. Hayhoe F. G. J. \& Cawley J. C. (1972) Acute leukemia: cellular morphology, cytochemistry and fine structure. In Clinics in Haematology (RoTH, S., Ed.) Vol. 1, p. 44. W. B. Saunders, New York.

11. Hoelzer D. (1973) Growth characteristics of a transferable acute leukemia in rats. J. natn. Cancer Inst. 50, 1321.

12. Husseini S., Fried W., Knospe W. H. \& Trobauch F. E., JR. (1976) Dynamics of leukemia and normal stem cells in leukemic RFM mice. Cancer Res. 36, 1784.

13. LeVY J. P. \& LECLERC J. C. (1976) The murine sarcoma virus-induced tumor: exception or general model in tumor immunology. Adv. Cancer Res. $24,1$.

14. LiN, H. S. L., Huber N. \& MURPhy W. H. (1969) Immunization of C58 mice to line Ib leukemia. Cancer Res. 29, 2157.

15. Lukasewycz O. A., Duffey P. S. \& MurPhy W. H. (1976) Immune mechanisms in leukemia: evaluation of immunocompetent cell populations. J. Immun. 114, 1491.

16. Lukasewycz O. A., Martinez D. \& Murphy W. H. (1975) Immune mechanisms in leukemia: protective capacity of major lymphoid cell compartments. J. Immun. 116, 976.

17. Möller G. (1974) Effect of B-cell mitogens on lymphocyte subpopulations. J. exp. Med. 139, 969.

18. Mosier D. E. \& Johnson B. M. (1975) Ontogeny of mouse lymphocyte function. II. Development of the ability to produce antibody is modulated by $\mathrm{T}$ lymphocytes. $J$. exp. Med. 141, 216. 
19. MurPhy S. \& Hersh E. (1978) Immunotherapy of leukemia and lymphoma. Seminars Hemat. $15,181$.

20. Murphy S. G. \& Lobuglio A. F. (1977) $\mathrm{L}_{2}$ C leukemia: a model of human acute leukemia. Fedn Proc. Fedn Am. Socs exp. Biol. 36, 2281.

21. Murphy W. H., URnovitz H. B., Maryanski J. L. \& Abrams G. D. (1978) Characterization of transplantable myelomonocytic leukemia WEHI-3B in syngeneic BALB/c mice. Proc. Soc. exp, Biol. Med. $157,556$.

22. Niezabitowski A., Fey F., Bender E. \& Rudolph M. (1975) Über eine transplantable, myeloische Hamster leukämie mit hohen preipheren Blutwerten und C-Partikel-Befund. II. Histologie und Zytochemie. Arch. Geschwulstforsch. 45, 232.

23. NOOTER K. \& BentzVelzen P. (1976) In vitro growth characteristics of virally transformed murine myeloid cells. Cancer Res. 36, 1246.

24. Plata E. J. \& Murphy W. H. (1972) Growth and hematologic properties of the BALB/wm strain of inbred mice. Lab. Animal Sci. 22, 712.

25. Prager M. D., Baechtel F. S., Ribble R. J., Ludden C. M. \& Mehta J. M. (1974) Immunological stimulation with modified lymphoma cells in a minimally responsive tumor-host system. Cancer Res. 34, 3203.

26. Preisler H. D., Bjronsson S. \& Mori M. (1977) Murine myeloid leukemia: I. Pathophysiology and drug sensitivity. Cancer Treatment Rep. 61, 1259.

27. Rölimghoff M., Starzinski-Powitz A., Pfizenmaier K. \& Wagner H. (1977) Cyclophosphamidesensitive $\mathbf{T}$ lymphocytes suppress the in vivo generation of antigen-specific cytotoxic $\mathrm{T}$ lymphocytes. J. exp. Med. 145, 455.

28. Röllinghoff M., Wagner H., Warner N. L. \& Nossal G. J. V. (1974) Activation of T lymphocytes against murine plasma cell tumors: a review of in vitro and in vivo studies. Israel J. Med. Sci. 10, 1001 .

29. SaARNI M. I. \& LinMan J. W. (1971) Myelomonocytic leukemia: disorderly proliferation of all marrow cells. Cancer 27, 122.

30. StAAB H. J. \& ANDERER F. A. (1977) Immunogenicity of tumor cells modified with various chemicals. Br. J. Cancer 35, 395.

31. URNovitz H. B. (1979) Negative regulation of the immune response to WEHI-3B myelomonocytic leukemia in syngeneic BALB/c mice. Ph.D. Thesis, The University of Michigan, Ann Arbor, MI, U.S.A.

32. VAN BeKkum D. M. \& HAgendeEK A. (1977) Relevance of the BN leukemia as a model for human acute myeloid leukemia. Blood Cells 3, 565.

33. Warner N. L., Moore M. A. S. \& Metcalf D. (1969) A transplantable myelomonocytic leukemia in BALB/c mice: cytology, karyotype and muramidase content. J. natn. Cancer Inst. 43, 963.

34. WRATHMell A. B. \& AleXANDER P. (1976) Immunogenicity of a rat leukemia of spontaneous origin (SAL). Br. J. Cancer 33, 181. 